Original Research Article

\title{
An extensive study: to assess the changing trends in prevalence and development of TTIs in non-remunerated blood donors at a tertiary care teaching hospital in Central India
}

\author{
Jain R ${ }^{1}$, Jain P $^{2}$ Mohit Kashiv $^{3}$, P. Desai ${ }^{4}$, U. Chudgar ${ }^{5}$, N. Choudhury ${ }^{6}$, V.K. Mahadik ${ }^{7}$ \\ ${ }^{1}$ Dr. Roopam Jain, ${ }^{2}$ Dr. Preeti Jain, ${ }^{3}$ Dr. Mohit Kashiv, C. R. Gardi Hospital and R. D. Gardi Medical College, Ujjain, \\ MP, India, ${ }^{4}$ Dr. P. Desai, Tata Memorial Hospital, Parel, Mumbai, ${ }^{5}$ Dr. U. Chudgar, Prathama Blood Centre, \\ Ahmedabad, ${ }^{6}$ Dr. N. Choudhury, Fortis Memorial Hospital, Delhi, ${ }^{7}$ Dr. V.K. Mahadik, C. R. Gardi Hospital and R. D. \\ Gardi Medical College, Ujjain, MP, India.
}

Corresponding Author: Dr. Preeti Jain, C.R. Gardi Hospital and R.D.Gardi Medical College, Ujjain, MP, India

\begin{abstract}
Background: Transfusion transmitted infections (TTI) are a major challenge to the transfusion services all over the world. The problem of TTIs is directly proportionate to the prevalence of the infection in the blood donor community which represents the general population. The purpose of this study is to analyze the status of Transfusion transmitted infections among seemingly healthy donors, targeting the non-remunerated blood donors (voluntary and replacement) during the period 2009- 2017. Material and method: A total of 84,975 blood donors were screened for seropositivity of HBsAg, anti-HCV, HIV, VDRL and malaria antigen at Regional blood transfusion center, in central India. Result: Out of 84,975 donations, 1906 (2.24\%) were sero-reactive for five blood transmitted infections. Among these, prevalence of HIV was $0.067 \%$ (57 donors), seroprevalence of HBsAg was 1.39\% (1184 donors), HCV showed 0.068\% (58 donors), VDRL showed $0.66 \%$ (564 donors) and malaria had $0.05 \%$ prevalence (43 donors). Conclusion: HBV is the most common infection among voluntary blood donors, followed by Syphilis. Replacement donors have higher prevalence of TTIs in overall donor population. A change to voluntary blood transfusion service would reduce the chances of post transfusion infections.
\end{abstract}

Keywords: Blood donors, TTIs, Seropositivity, Prevalence, Voluntary donors, Replacement donors

\section{Introduction}

Transfusion transmitted infections impose significant burden on Blood Safety. The incidence rates across the world are difficult to calculate given the asymptomatic and often latent nature of the disease prior to clinical presentation. Every blood transfusion therefore carries a potential risk for transmissible diseases [1].

Transmission of diseases still occurs, primarily because of the inability of the test to detect the disease in the 'window' phase of their infection, high cost of screening, a lack of funds and trained personnel, immunologically variant viruses, non-seroconverting chronic or immuno silent carriers and inadvertent laboratory testing errors [2]. Blood transfusion is a lifesaving measure in various medical and surgical emergencies. Transfusion medicine, apart from being important for the medical treatment of each patient, also

Manuscript received: $25^{\text {th }}$ July 2018

Reviewed: $4^{\text {th }}$ August 2018

Author Corrected: $10^{\text {th }}$ August 2018

Accepted for Publication: $16^{\text {th }}$ August 2018 has great public health importance. National blood policy adopted by Ministry of Health and Family Welfare in 2002, with major objective to reiterate firmly the Government's commitment to provide safe and adequate quantity of blood, blood components and blood products [3].

Currently the transfusion transmitted infections are divided into four divisions namely, viral, bacterial, parasitic and emerging. However, to ensure safe blood donation, NACO (National Aids Control Organization) recommends the testing of 5 TTIs. They are HIV, HBV, HCV, Malaria and Syphilis [4].

Voluntary unpaid blood donors are vital for ensuring a sufficient, stable blood supply. A well-established voluntary unpaid blood donor program can contribute to a significant reduction in the risk for TTIs. India reports the greatest increase in the number of voluntary unpaid blood donations from 3.6 million in 2007 to 4.6 million 


\section{Original Research Article}

in 2008 and from 7.4 million in 2012 to 8.5 million in 2013 [5]. This study focuses to assess the yearly trends and development of TTIs during a study period of 9 years from 2009- 2017 at Regional Blood Transfusion Center in central India.

\section{Aims and Objectives}

1. To evaluate the seroprevalence of TTIs among apparently healthy donors.

2. To assess seroprevalence of TTI among different donor groups.

3. To observe the yearly trends and variations in the prevalence of TTIs.

\section{Material and Method}

Place of study-Regional blood transfusion center, C R Gardi Hospital and R D Gardi Medical College, Ujjain.

Type of study- Cross-sectional and Observational Study.

Duration of study- The study was performed among all the units of blood collected during a period of nine years (2009-2017).

Inclusion criteria- The subjects included all replacement and voluntary blood donors. Donors were selected by taking history, clinical examination and following donors' selection criteria according to the Indian FDA rules and regulations for donor selection. Written consent was taken. Blood was collected in blood bags containing anticoagulant-preservative solution. About 3-5 $\mathrm{ml}$ of donor blood was also collectedin pilot tube for ABO grouping, Rh typing and testing of infectious diseases.

Procedure Planned- Donor samples were analyzed for the TTIs like Malaria, HIV, Syphilis and Hepatitis, with routine examinations of blood grouping and $\mathrm{Rh}$ typing.

All the samples were screened for Hepatitis B surface antigen (HBs Ag), HIV (1and 2), Hepatitis C virus (HCV) by ELISA method for determination of respective antigens and antibodies in human serum/ plasma. Screening for Syphilis was done Syphilis Rapid Test Strips to detect antibodies for Treponema Pallidum in serum/ plasma/whole blood. Malaria parasite was screened by gold standard light microscopy.

Additional data analysis was conducted to examine the prevalence trends associated with each infection.

Data Collection- Information regarding donor was extracted from Donor register. Donor register is filled for eligible donors before blood collection. The data included relevant history, clinical examination findings and results for HIV, Syphilis, HBV, HCV, and Malaria.

Data Analysis- Computerized compilation and coding of collected data was done. All statistical analysis was made by using Stata (version 12, college station, Texas, USA). For comparing various categorical variables we used 'Chi-square' test of significance, 'Yates correction' was used at relevant places. 'Z-test' of variation between two means was applied to compare various means at 5\% level of significance. P-value of $<0.05$ was considered statistically significant

\section{Result}

A total of 84,975 donors were enlisted in the study. Of these, $24,135(28.40 \%)$ were voluntary and $60,840(71.60 \%)$ replacement donors. Males outnumbered females with 79,137 (93.13\%) donations while only 5,838 (6.87\%) donors were females. Among these, 55,565 (65.39\%) of the donors aged from 18 to 30 years, 21,125 (24.86\%) from 31 to 40 years and $8,285(9.75 \%)$ were in the $41-60$ years age group.

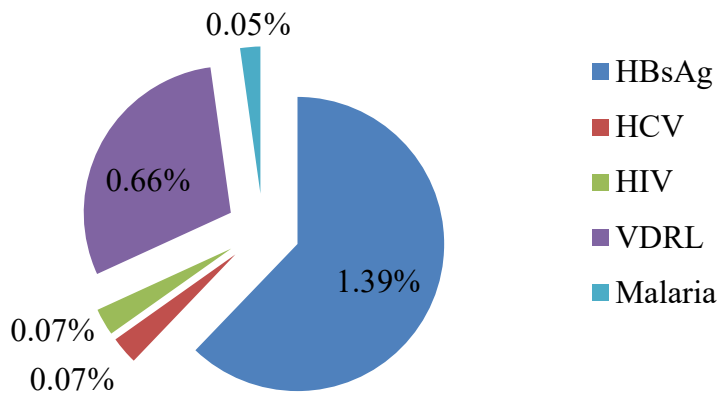

Fig 01: Seroprevalence of various TTIs. Out of total 84,975 donors, 1906 were found seropositive for various TTIs. 


\section{Original Research Article}

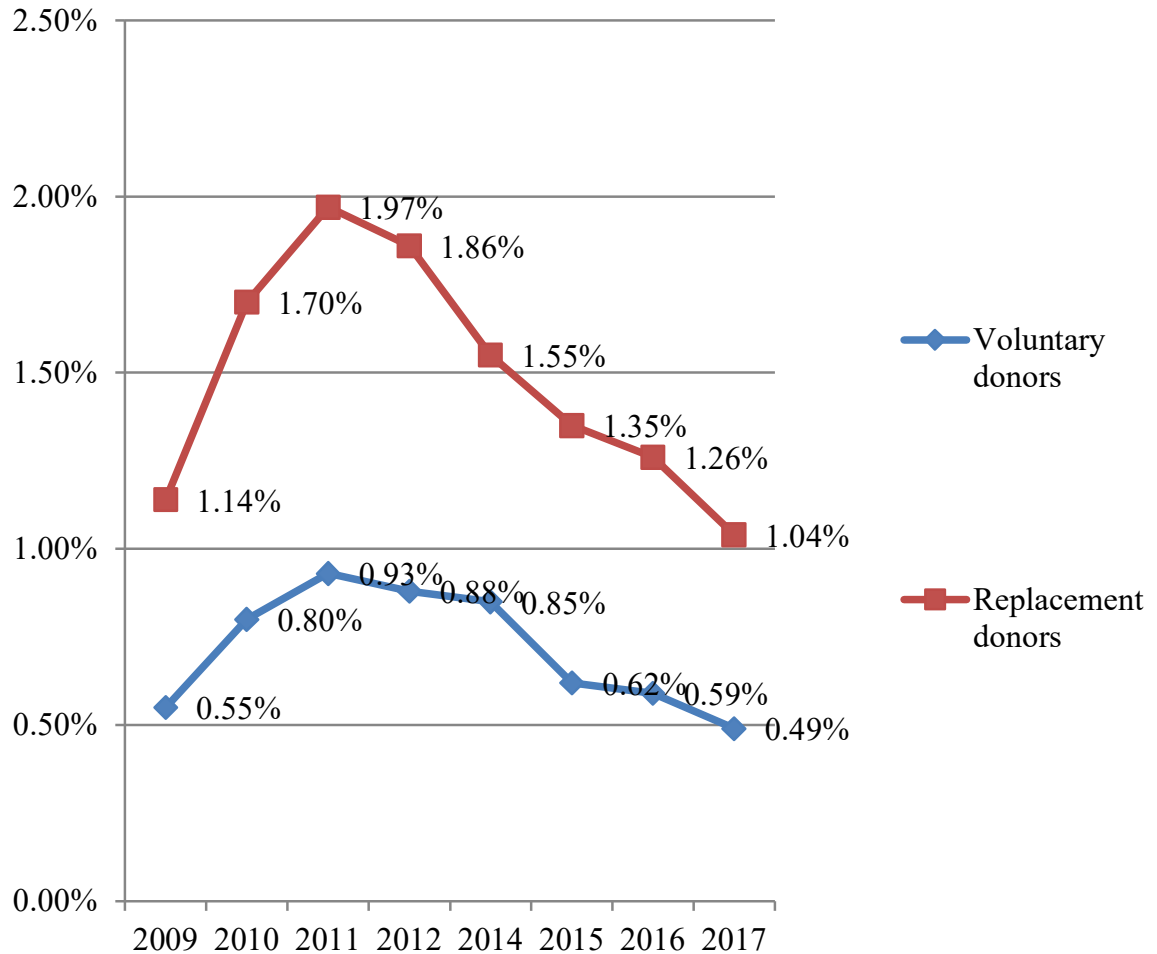

Fig. 02: Annual trends in the prevalence of overall TTI among voluntary and replacement donors. Out of 84,975 donors, 1906 donors were found seropositive for various TTIs, of which 1296 (68\%) were replacement donors and rest $610(32 \%)$ were Voluntary donors.

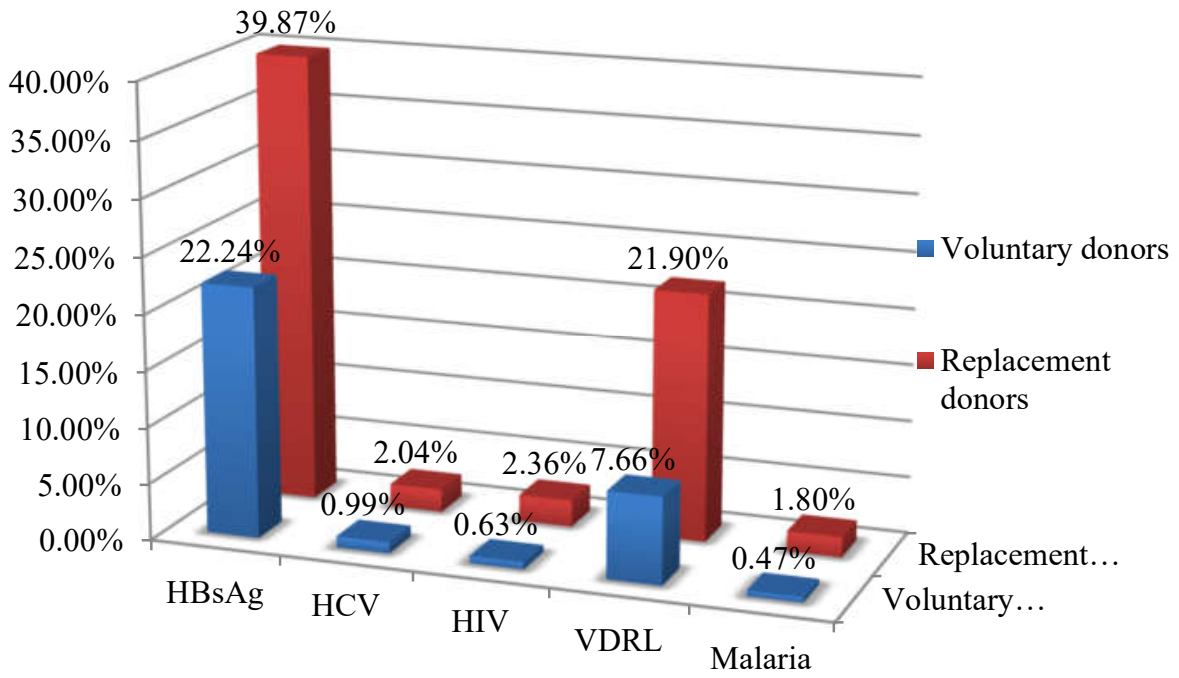

Fig. 03: Seroprevalence of various TTIs among different blood donors. Out of 1906 seropositive donors, 1296 were replacement donors and rest, 610 were voluntary donors. 


\section{Original Research Article}

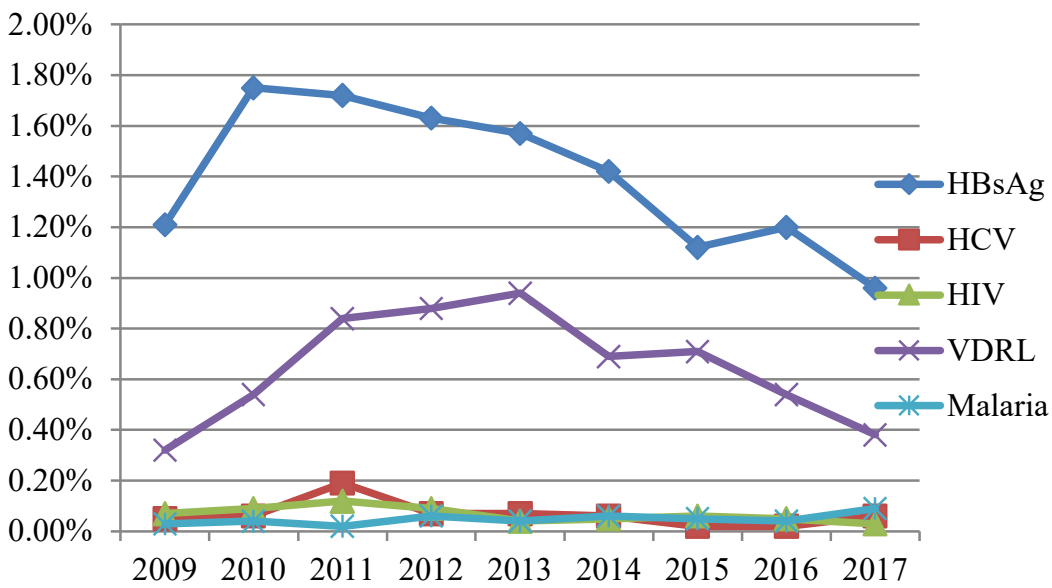

Fig.-04: Annual trends of each TTI over the study period 2009-2017

Table- 01: Incidence of TTI amongst voluntary and replacement donors during nine year study period (2009-2017).

\begin{tabular}{|c|c|c|c|c|}
\hline Year & Totaldonors & $\begin{array}{c}\text { Seropositive } \\
\text { Replacement Donors }\end{array}$ & $\begin{array}{c}\text { Seropositive } \\
\text { Voluntary Donors }\end{array}$ & $\begin{array}{c}\text { Total } \\
\text { Seropositive Donors }\end{array}$ \\
\hline $\mathbf{2 0 0 9}$ & 5594 & $64(1.14 \%)$ & $31(0.55 \%)$ & 95 \\
\hline $\mathbf{2 0 1 0}$ & 8979 & $153(1.7 \%)$ & $72(0.80 \%)$ & 225 \\
\hline $\mathbf{2 0 1 1}$ & 9156 & $181(1.97 \%)$ & $85(0.93 \%)$ & 266 \\
\hline $\mathbf{2 0 1 2}$ & 8135 & $152(1.86 \%)$ & $72(0.88 \%)$ & 224 \\
\hline $\mathbf{2 0 1 3}$ & 9230 & $168(1.82 \%)$ & $79(0.85 \%)$ & 247 \\
\hline $\mathbf{2 0 1 4}$ & 12065 & $188(1.55 \%)$ & $89(0.74 \%)$ & 277 \\
\hline $\mathbf{2 0 1 5}$ & 11178 & $151(1.35 \%)$ & $69(0.62 \%)$ & 212 \\
\hline $\mathbf{2 0 1 6}$ & 11378 & $144(1.26 \%)$ & $68(0.59 \%)$ & 140 \\
\hline $\mathbf{2 0 1 7}$ & 9160 & $95(1.04 \%)$ & $45(0.49 \%)$ & $\mathbf{1 9 0 6}$ \\
\hline Total & $\mathbf{8 4 9 7 5}$ & $\mathbf{1 2 9 6}$ & $\mathbf{6 1 0}$ & \\
\hline
\end{tabular}

Table-02: Incidence of HIV, HBsAg, HCV, Syphilis and Malaria in blood donors during nine year study period (2009- 2017).

\begin{tabular}{|c|c|c|c|c|c|c|}
\hline Year & Donors & HIV & HBsAg & HCV & VDRL & Malaria \\
\hline $\mathbf{2 0 0 9}$ & 5594 & $4(0.07 \%)$ & $68(1.21 \%)$ & $3(0.05 \%)$ & $18(0.32 \%)$ & $2(0.03 \%)$ \\
\hline $\mathbf{2 0 1 0}$ & 8979 & $8(0.09 \%)$ & $158(1.75 \%)$ & $6(0.06 \%)$ & $49(0.54 \%)$ & $4(0.04 \%)$ \\
\hline $\mathbf{2 0 1 1}$ & 9156 & $11(0.12 \%)$ & $158(1.72 \%)$ & $18(0.19 \%)$ & $77(0.84 \%)$ & $2(0.02 \%)$ \\
\hline $\mathbf{2 0 1 2}$ & 8135 & $8(0.09 \%)$ & $133(1.63 \%)$ & $6(0.07 \%)$ & $72(0.88 \%)$ & $5(0.06 \%)$ \\
\hline $\mathbf{2 0 1 3}$ & 9230 & $4(0.04 \%)$ & $145(1.57 \%)$ & $7(0.07 \%)$ & $87(0.94 \%)$ & $4(0.04 \%)$ \\
\hline $\mathbf{2 0 1 4}$ & 12065 & $6(0.05 \%)$ & $172(1.42 \%)$ & $8(0.06 \%)$ & $84(0.69 \%)$ & $7(0.06 \%)$ \\
\hline $\mathbf{2 0 1 5}$ & 11178 & $7(0.06 \%)$ & $125(1.12 \%)$ & $2(0.02 \%)$ & $80(0.71 \%)$ & $6(0.05 \%)$ \\
\hline $\mathbf{2 0 1 6}$ & 11378 & $6(0.05 \%)$ & $137(1.20 \%)$ & $2(0.02 \%)$ & $62(0.54 \%)$ & $5(0.04 \%)$ \\
\hline $\mathbf{2 0 1 7}$ & 9160 & $3(0.03 \%)$ & $88(0.96 \%)$ & $6(0.06 \%)$ & $35(0.38 \%)$ & $8(009 \%)$ \\
\hline Total & 84975 & $57(0.067 \%)$ & $1184(1.39 \%)$ & $58(0.068 \%)$ & $564(0.663 \%)$ & $43(0.050 \%)$ \\
\hline
\end{tabular}

Out of the 84,975 blood donors, 1,906 (2.24\%) were tested reactive for various blood transmitted infections (Fig. 01). Out of these seropositive donors, 1,296 (68\%) were replacement donors (Fig. 02). The prevalence for HIV was $0.067 \%$ ( 57 donors) in total donors, more in replacement ( 45 donors) as compared to voluntary (12 donors). The seroprevalence 


\section{Original Research Article}

of HBsAg in total donors was 1.39\% (1184 donors). Replacement donors (760 donors) had a high incidence as compared to voluntary donors ( 424 donors). The seropositivity of HCV in total donors was $0.068 \%$ ( 58 donors), with a higher seropositivity (39 donors) in replacement donor group. The seroprevalence of VDRL among all donors was $0.66 \%$ (564 donors) with the replacement donors (418 donors) having a higher prevalence as compared to voluntary donors (146 donors). Forty three $(0.05 \%)$ blood donors tested positive for malaria parasite. In all the five diseases the incidence was high in males and in replacement donors (Fig. 03) (Table- 01). The concurrent rates for seroreactivity were highest for HBsAg followed by VDRL, HCV, HIV, and malaria in descending order (Fig. 04) (Table- 02).

\section{Discussion}

Transfusion of blood and blood components, as a specialized modality of patient management saves millions of lives worldwide each year and reduces morbidity. It is well known that blood transfusion is associated with a large number of complications, some are only marginal and others are potentially life threatening, demanding for thorough pretransfusion testing and screening particularly for TTIs.

In our study, the number of replacement donors $(71.60 \%)$ was higher than voluntary blood donors $(28.40 \%)$. The number of replacement donors was consistently higher than voluntary donors over the years. However, there was a trend for increasing voluntary blood donation in the recent years and the percentage of voluntary donations increased in the last few years to $33.2 \%$. This increase was seen due to strong blood donor motivation strategies over the years.

Of the total donation received, majority $(93.13 \%)$ were from male donors. This could be explained on the basis that the Indian women have a very high incidence of anemia especially in the child bearing age and hence are likely to face disqualification while being screened for blood donation.

Overall prevalence of TTIs estimated in our study $(2.24 \%)$ is significantly lower than the prevalence found in other studies $[6,7,8,10]$. This studyhavealso shown high seropositivity rates of TTIs in replacement donors compared to voluntary donors, a similar finding was noted in other studies $[2,7,9,11,13,16]$.

Seroprevalence of HIV, HBsAg, HCV, VDRL and malaria found in this study are $0.067 \%, 1.39 \%, 0.068 \%$, $0.66 \%$ and $0.05 \%$ respectively. Hepatitis $\mathrm{B}$ and $\mathrm{C}$ and HIV units are of major concern due to carrier state and complications associated with these infections.Hepatitis $\mathrm{B}$ virus (HBV), hepatitis $\mathrm{C}$ virus (HCV), Human immune deficiency virus (HIV) and syphilis are the most important lethal agents in transfusion transmitted infections (TTIs) and it remains a large health care burden globally. The incidence rates across the world are difficult to calculate given the asymptomatic and often latent nature of the disease prior to clinical presentation. Every blood transfusion therefore carries a potential risk for transmissible diseases. HBV incidence is higher in our population $(1.39 \%)$ as compared to other similar studies [2,6,7,13,14]. HBV positivity indicates a carrier state or an active infection. These seropositive donors may progress to develop chronic hepatitis, cirrhosis, and even progress to hepatocellular carcinomas.

A WHO report states that the viral dose in HIV transmission through blood is so large that one HIV positive transfusion leads to death, on an average, after 2 years in children and after three to 5 years in adults [16]. HIV seropositive donors were $0.067 \%$ of the total $(84,975)$ blood donors studied, which is lower than the published data in other studies $[6,7,8,9,10,13,14]$.

VDRL reactive donors were estimated at $0.66 \%$ in this study which is greater than calculated in other studies $[2,6,7,9,12,13,14]$. Transfusion transmitted syphilis is not a major hazard in modern blood transfusion therapy. It is not the transmission of syphilis that is worrisome, being a sexually transmitted disease, it's presence points towards donor's indulgence in "high risk" behavior and consequent higher risk of exposure to infections like HIV and hepatitis [17].

Of the major transfusion transmitted diseases, malaria is a major cause of TTPI in tropical countries. Blood transfusion possesses a problem because the parasites keep their infective activity for at least 14 days in blood bottles stored at $4{ }^{\circ} \mathrm{C}$, a leading cause of TTPI [18].

A moderately fluctuating trend was observed in our series for all infections with a mild reduction in hepatitis B and syphilis infection in the recent years (Fig.04). Improvements must be made in donor selection criteria and screening for infectious diseases in order to provide a safe blood supply. Blood can save lives; however, it also carries the potential to transmit life-threatening infections.

Methods to ensure a safety blood supply should be encouraged. For that, screening with a better selection of donors and use of sensitive screening tests including nucleic acid testing technology should be implemented. 


\section{Original Research Article}

\section{Conclusion}

In this study the overall prevalence of TTIs was estimated at $2.24 \%$, with seroprevalence of HIV, HBsAg, HCV, VDRL and malaria found in this study are $0.067 \%, 1.39 \%, 0.068 \%, 0.66 \%$ and $0.05 \%$ respectively. There was increased seropositivity rate amongst the replacement donors as compared to the voluntary donors.

Blood transfusion is an important preventable modality of spread of TTIs. It is a time of urgent and concrete measures to eliminate the transfusions from paid donors and to improve the safety of the blood supply. To provide proper transfusion facilities to underdeveloped areas.

These conditions can be overcome by development of a fair and organized system of blood screening and transfusion.

Despite stringent donor screening and testing practices, safe blood free from TTIs remains an elusive goal because the threat of TTIs agents entering the blood supply is not static. This study showed growing evidence in the burden of TTIs in blood donors. The field of transfusion medicine has encountered huge precautions in providing safe blood. Prevention of spread of TTIs should be the main goal at the current time.

Findings: Nil; Conflict of Interest: None initiated Permission from IRB: Yes

Ethical approval: All procedures performed in studies involving human participants were in accordance with the ethical standards of the institutional and/or national research committee and with the 1964 Helsinki declaration and its later amendments or comparable ethical standards.

Informed consent: Informed consent was obtained from all individual participants included in the study.

\section{References}

1. Bhawani Y, Rao PR, Sudhakar V: Seroprevalence of transfusion transmissible infections among blood donors in a tertiary care hospital of Andhra Pradesh. Biol Med, 2010, 2(4):45-48.

2. Fernandes H, D'souza PF, D'souza PM. Prevalence of transfusion transmitted infections in voluntary and replacement donors. Indian J Hematol Blood Transfus. 2010 Sep;26(3):89-91. doi: 10.1007/s12288-010-00440 . Epub 2010 Oct 21.
3. NACO: National Blood Policy, National AIDS Control Organization, Ministry of Health and Family Welfare Government of India, New Delhi, 2007 [www.naco.nic.in]

4. Neelam Marwaha: Voluntary blood donation in India: Achievements, expectations and challenges. Asian J Transfus Sci. 2015 Apr; 9 (Suppl. 1): S1-S2. doi: 10.4103/0973-6247.157011

5. Global status report on blood safety and availability 2016. Geneva: World Health Organization; 2017.

6. Dushyant Singh Gaur, Gita Negi: Trends of transfusion transmissible diseases among blood donors at Uttarakhand, India. Indian Journal of Community Medicine, Vol. 39, No. 3, July-September, 2014, pp. 183-186

7. R.N. Makroo, Vikas Hegde, Mohit Chowdhry, Aakanksha Bhatia, and N.L. Rosamma Seroprevalence of infectious markers \& their trends in blood donors in a hospital based blood bank in North India. Indian J Med Res. 2015 Sep; 142(3): 317-322.

8. Jain R, Jain P, Mahadik V, Choudhury N: Prevalence And Incidence Of Transfusion Transmitted Infections Amongst VNRBDs In Central India. Natl J Integr Res Med, 2015; 6(4): 82-85

9. Garg S, Mathur DR, Garg DK. Comparison of seropositivity of $\mathrm{HIV}, \mathrm{HBV}, \mathrm{HCV}$ and syphilis in replacement and voluntary blood donors in western India. Indian J Pathol Microbiol. 2001 Oct; 44 (4): 409-12.

10. Buseri FI, Muhibi MA, Jeremiah ZA. Seroepidemiology of transfusion-transmissible infectious diseases among blood donors in Osogbo, south-west Nigeria. Blood Transfus. 2009 Oct;7(4):293-9. doi: 10. 2450/2009.0071-08.

11. Tulika Chandra, S. Nishat Fatima Rizvi, and Devisha Agarwal: Decreasing Prevalence of Transfusion Transmitted Infection in Indian Scenario. The Scientific World Journal Volume, 2014, Article ID 173939, 4 pages

12. N Kocak, S Hepgul, S Ozbayburtluet al: Trends in Major Transfusion-transmissible Infections among Blood Donors over 17 Years in Istanbul, Turkey The Journal of International Medical Research, 2004; 32: $671-675$ 


\section{Original Research Article}

13. Pallavi P, Ganesh CK, Jayashree K, Manjunath GV. Seroprevalence and trends in transfusion transmitted infections among blood donors in auniversity hospital blood bank: a 5 year study. Indian J Hematol Blood Transfus. 2011 Mar; 27 (1): 1-6. doi: 10.1007/s12288010-0047-x. Epub 2010 Dec 14.

14. Chandekar SA, Amonkar GP, Desai HM, Valvi N, Puranik GV. Seroprevalence of transfusion transmitted infections in healthy blood donors: A 5-year Tertiary Care Hospital experience. J Lab Physicians, 2017; 9:283-7.

15. Choudhury N, Ramesh V, Saraswat S, Naik S: Effectiveness of mandatory transmissible diseases screening in Indian blood donors. The Indian Journal of Medical Research, 1995.[01 Jun 1995, 101:229-232]
16. Arora D, Arora B, Khetarpal A. Seroprevalence of $\mathrm{HIV}, \mathrm{HBV}, \mathrm{HCV}$ and syphilis in blood donors in Southern Haryana. Indian J Pathol Microbiol. 2010 Apr-Jun; 53 (2): 308-9. doi: 10.4103/0377- 4929. 64295.

17. Ness PM: Bacterial and protozoal infections transmitted by transfusion. In: Principles of Transfusion Medicine. EC Rossi, TL Simon, GS Moss, (Eds.), 1st Edn; Williams \& Wilkins, Baltimore, 1991: pp. 611-618.

18. K. Park. Epidemiology of Communicable Diseases In: Park's Textbook of Preventive and Social Medicine, 24th edition, Bhanot Publishers, 2017, p.271.

\section{How to cite this article?}

Jain R, Jain P, Mohit Kashiv, P. Desai, U. Chudgar, N. Choudhury, V.K. Mahadik. An extensive study: to assess the changing trends in prevalence and development of TTIs in non-remunerated blood donors at a tertiary care teaching hospital in Central India. Trop J Path Micro 2018; 4(6):448-454.doi:10.17511/jopm.2018.i06.06. 